\title{
ANATOMIC STUDY OF LOCALIZATION OF FORAMEN OVALE, CAROTID CANAL, JUGULAR FORAMEN USING HENLE'S SPINE AS SURFACE LANDMARK IN SOUTH INDIAN ADULT SKULLS
}

\author{
Yogitha Ravindranath', Jyotsna Bailur², Vijay Kishan³, Rema Devi ${ }^{4}$ \\ ${ }^{1}$ Associate Professor, Department of Anatomy, St. John's Medical College, Bangalore. \\ ${ }^{2}$ Post Graduate, Department of Anatomy, St. John's Medical College, Bangalore. \\ 3Post Graduate, Department of Anatomy, St. John's Medical College, Bangalore. \\ 4 Professor, Department of Anatomy, St. John's Medical College, Bangalore.
}

\section{ABSTRACT}

\section{BACKGROUND}

Henle's Spine (HS) is a small bony prominence, anterior to the supramastoid pit, at the postero-superior margin of the external acoustic meatus. Localization of cranial structures using this anatomical landmark is of immense surgical importance to identify and avoid surgical morbidities.

\section{AIMS}

Considering the limited number of research articles describing its anatomy in South Indian skulls, present study was conducted to estimate the location and the difference between the right and left sides of the skull base foramen by using HS as surface landmark, which can act as a guide to various approaches of the skull base surgeries.

\section{SETTING AND DESIGN}

Cross-sectional observational study.

\section{MATERIALS AND METHODS}

Twenty nine (58 sides) adult South Indian skulls with prominent HS were studied. Following distances on both right and left sides of the skulls were measured from tip of HS to anterior margin and posterior margin of foramen ovale (HS-AMFO, HS-PMFO); posterolateral and medial jugular foramen (HS-PLJF, HS-PMJF); lateral and medial margin of carotid canal (HS-LMCC, HS-MMCC) using digital calliper of $0.01 \mathrm{~mm}$ accuracy.

\section{STATISTICAL ANALYSIS} ' $\mathrm{t}$ ' test.

Data was analysed using SPSS version 16. Mean, Standard deviation was calculated. Side differences were estimated using paired

\section{RESULTS}

The mean distance from HS-AMFO was $35.96 \pm 2.05 \mathrm{~mm}$, HS-PMFO was $42.57 \pm 2.38 \mathrm{~mm}$; HS-PLJF $22.82 \pm 2.12 \mathrm{~mm}$, HS-PMJF was $34.08 \pm 2.48 \mathrm{~mm}$; HS-LMCC was $26.68 \pm 1.95 \mathrm{~mm}$, HS-MMCC was $32.27 \pm 2.22 \mathrm{~mm}$. There was a significant difference noted between right and left sides $(\mathrm{p}<0.05)$ of Henle's spine to posterolateral margin of jugular foramen.

\section{CONCLUSION}

Henle's spine can be used as a reliable landmark to locate the deeper structures of skull base. However, the possibility of side difference among the population should be kept in mind prior to surgery.

\section{KEYWORDS}

Henle's Spine, Suprameatal Spine, Skull Base Approach, Carotid Canal, Foramen Ovale, Jugular Foramen, Surface Landmark.

HOW TO CITE THIS ARTICLE: Ravindranath Y, Bailur J, Kishan V, et al. Anatomic study of localization of foramen ovale, carotid canal, jugular foramen using Henle's spine as surface landmark in South Indian adult skulls. J. Evolution Med. Dent. Sci. 2016;5(53): 3569-3572, DOI: $10.14260 /$ jemds/2016/822

\section{INTRODUCTION}

Skull base is a very complex region having many neural and vascular connections with the cranial fossae, paranasal sinus, orbit and the neck. It represents one of the latest surgical

Financial or Other, Competing Interest: None.

Submission 25-04-2016, Peer Review 18-06-2016,

Acceptance 24-06-2016, Published 04-07-2016.

Corresponding Author:

Dr. Yogitha Ravindranath,

Associate Professor

Department of Anatomy,

St. John's Medical College,

Bangalore-560034.

E-mail:yogi3110@gmail.com

DOI: $10.14260 /$ jemds $/ 2016 / 822$ frontiers and poses surgical challenges for the otolaryngologists and the neurosurgeons.(1,2) Otologic and neurotologic skull base surgery requires a thorough knowledge of the temporal bone anatomy, as the temporal bone is one of the great gateways of the skull.(3) Its petrous portion gives the passage for the internal carotid artery, vestibulocochlear nerve and facial nerve.(4) Therefore, in order to identify and safely approach the vital structures in the skull base during surgeries, many accessible anatomical surface landmarks like the mastoid tip, the digastric muscle, the spine of Henle, the cribriform area, the temporal line, the external auditory canal and the root of the zygomae(2) are used to relate and access the underlying anatomical structures. 
The Henle's Spine (HS)/spina suprameatica/spina suprameatalis/meatal spine or spina meatus, is a small bony prominence anterior to the supramastoid pit at the posterosuperior margin of the bony external acoustic meatus (Figure 1). Jacob Henle (1809-1885) reported it as a reliable guide in locating the antrum during the surgical intervention of the mastoid region.(5) Considering the key position, superficial accessibility and the clinical importance, present study was carried out to estimate the distance and the bilateral variability between Henle's Spine (HS) on the temporal bone to the clinically important foramina i.e. foramen ovale, carotid canal and jugular foramen on the dry adult South Indian skulls (Figure 2).

\section{MATERIALS AND METHODS}

Cross-sectional observational study was done on twenty nine (58 sides) adult cadaveric skulls with a prominent HS selected from the purposive sampling technique from the collection of skulls at the Department of Anatomy, St. John's Medical College, Bangalore. The skulls which showed pathological changes and destruction at the cranial base were excluded from the present study.

Using HS as surface landmark ${ }^{(6,7)}$ two imaginary lines, the spinopterygoidal and the bispinal lines were determined. The spinopterygoidal line extends through the medial margin of foramen ovale to the posterior margin of the medial pterygoid plate (Figure 3). The bispinal line extends between the two HS (Figure 3). The area in the form of a triangle, enclosed between the spinopterygoidal, bispinal and the midsagittal lines was defined as parapetrosal triangle (Figure 4). Along the imaginary lines defined, the following distances were measured (Using digital Vernier caliper of $0.01 \mathrm{~mm}$ of accuracy) from HS to foramen ovale, jugular foramen and carotid canal of the middle cranial base. The following distances were measured both on right and left sides of the skull.

1. The distance from the HS to the anterior margin and posterior margin of foramen ovale (HS-AMFO, HS-PMFO).

2. The distance from the HS to the posterolateral and posteromedial jugular foramen (HS-PLJF, HS-PMJF).

3. The distance from the HS to the lateral and medial margin of carotid canal (HS-LMCC, HS-MMCC).

Statistical analysis was done using SPSS version 16 . Mean and standard deviation were calculated. The side differences were compared using paired ' $t$ ' test, ' $p$ ' value $\leq 0.05$ was considered statistically significant.

\section{RESULTS}

The range, mean and SD of distances from the HS to three important anatomical landmarks on the spinopterygoidal and bispinal lines and in the parapetrosal triangle is tabulated below (Table 1). The values are given in $\mathrm{mm}$ and as Mean \pm Standard Deviation (SD).

\begin{tabular}{|c|c|c|c|c|c|}
\hline \multirow{2}{*}{$\begin{array}{c}\text { Distance } \\
\text { (mm) } \\
n=29\end{array}$} & \multicolumn{2}{|c|}{ Range } & \multicolumn{2}{|c|}{ Mean \pm SD } & \multirow[b]{2}{*}{ 'p' value } \\
\hline & Right & Left & Right & Left & \\
\hline HS-AMFO & $\begin{array}{l}51.40- \\
37.19\end{array}$ & $\begin{array}{l}45.67- \\
36.87\end{array}$ & $\begin{array}{c}42.90 \pm \\
2.24\end{array}$ & $\begin{array}{c}42.24 \pm \\
1.96\end{array}$ & 0.109 \\
\hline
\end{tabular}

\begin{tabular}{|c|c|c|c|c|c|}
\hline \multirow{2}{*}{ HS-PMFO } & $42.18-$ & $39.57-$ & $36.01 \pm$ & $35.92 \pm$ & 0 \\
& 31.83 & 32.51 & 2.34 & 1.74 & 0.78 \\
\hline \multirow{2}{*}{ HS-PLJF } & $27.08-$ & $28.73-$ & $22.33 \pm$ & $23.31 \pm$ & $0.023^{*}$ \\
& 19.15 & 20.70 & 2.12 & 2.03 & \\
\hline \multirow{2}{*}{ HS-PMJF } & $38.60-$ & $40.32-$ & $34.09 \pm$ & $34.07 \pm$ & 0.95 \\
& 29.74 & 29.19 & 2.49 & 2.40 & \\
\hline \multirow{2}{*}{ HS-LMCC } & $30.34-$ & $30.85-$ & $26.49 \pm$ & $26.87 \pm$ & 0 \\
& 22.32 & 23.58 & 2.04 & 1.88 & \\
\hline \multirow{2}{*}{ HS-MMCC } & $38.63-$ & $36.06-$ & $32.46 \pm$ & $32.09 \pm$ & \multirow{2}{*}{0.14} \\
\hline & 29.00 & 29.07 & 2.36 & 2.08 & \\
\hline \\
Table 1: The Range, Mean, SD of Specific Distance \\
Measured on Right and Left Sides of Twenty \\
Nine Adult Dry South Indian Skulls \\
\hline
\end{tabular}

*Statistically significantly difference $(\mathrm{p}<0.05)$ noted for distance of HS to posterolateral margin of jugular foramen. HSAMFO, HS-PMFO- distance from the HS to the anterior margin and posterior margin of foramen ovale: HS-PLJF, HS-PMJFdistance from the HS to the posterolateral and posteromedial margin of jugular foramen: HS-LMCC, HS-MMCC-distance from the HS to the lateral and medial margin of carotid canal.

\begin{tabular}{|c|c|c|c|}
\hline $\begin{array}{c}\text { Anatomic } \\
\text { Landmarks }\end{array}$ & $\begin{array}{c}\text { ULUG et al } \\
\mathbf{2 0 0 5} \\
\text { Turkey } \\
\text { n=46 }\end{array}$ & $\begin{array}{c}\text { Biswabina } \\
\text { Ray et al } \\
\mathbf{2 0 1 1} \text {, India } \\
\mathbf{n = 3 9}\end{array}$ & $\begin{array}{c}\text { Present } \\
\text { Study, } \\
\text { India } \\
\mathbf{n}=\mathbf{2 9}\end{array}$ \\
\hline HS-PM FO & $37.93 \pm 1.85$ & $38.2 \pm 2.5$ & $35.96 \pm 2.05$ \\
\hline HS-AM FO & $44.71 \pm 2.81$ & $45.1 \pm 2.7$ & $42.57 \pm 2.38$ \\
\hline HS-PLJF & $23.40 \pm 2.37$ & $32.0 \pm 5.4$ & $22.82 \pm 2.12$ \\
\hline HS-PMJF & $34.35 \pm 2.01$ & - & $34.08 \pm 2.48$ \\
\hline HS-LMCC & $28.70 \pm 3.74$ & $27.6 \pm 2.6$ & $26.68 \pm 1.95$ \\
\hline HS-MMCC & $34.50 \pm 2.08$ & $35.9 \pm 2.9$ & $32.27 \pm 2.221$ \\
\hline \multicolumn{4}{|c|}{ Table 2: Comparison of the Present } \\
\multicolumn{4}{|c}{ Study with the Previous Studies } \\
\hline
\end{tabular}
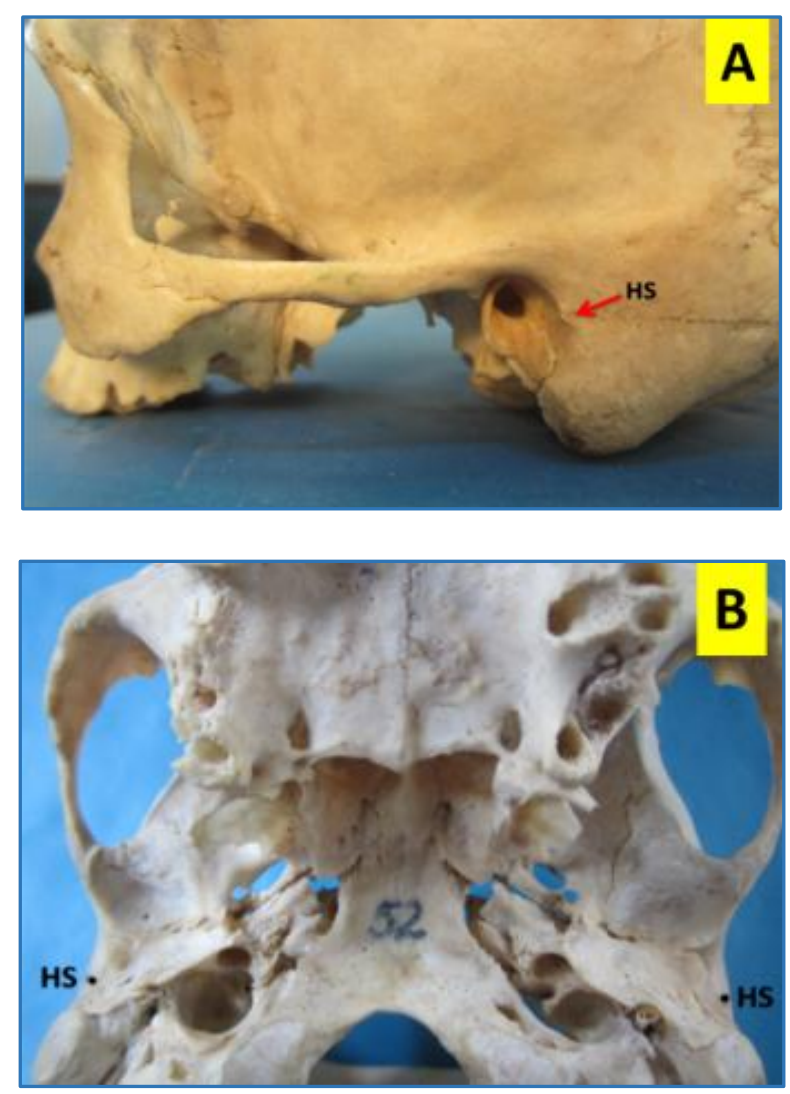


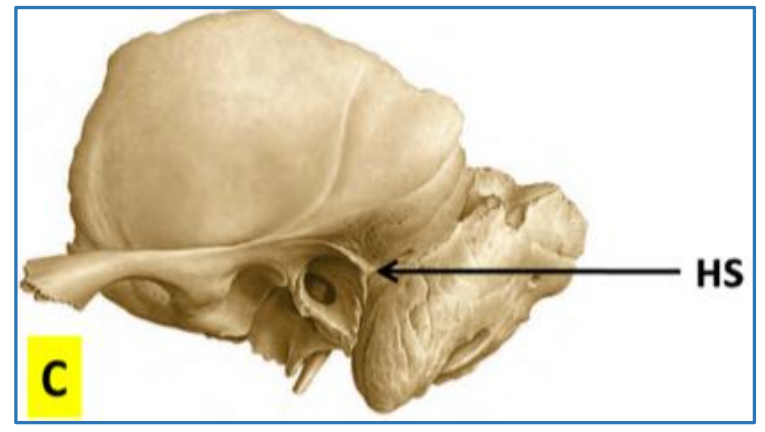

Fig. 1: Images $A, B, C$ showing the Location of the Henle Spine (HS) in the Lateral Skull View, Base of the Skull and in the Temporal Bone Respectively

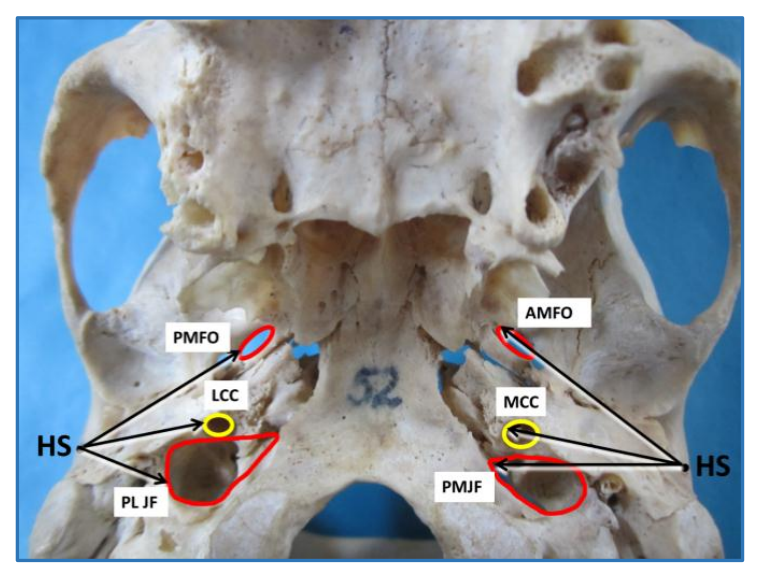

Fig. 2: Figure showing the Measurement of Distance from HS to the Anatomical Landmarks at the Base of the Skull. HS-AMFO, HS-PMFO, HS-PL JF, HS-PMJF, HS-LMCC, HS-MMCC
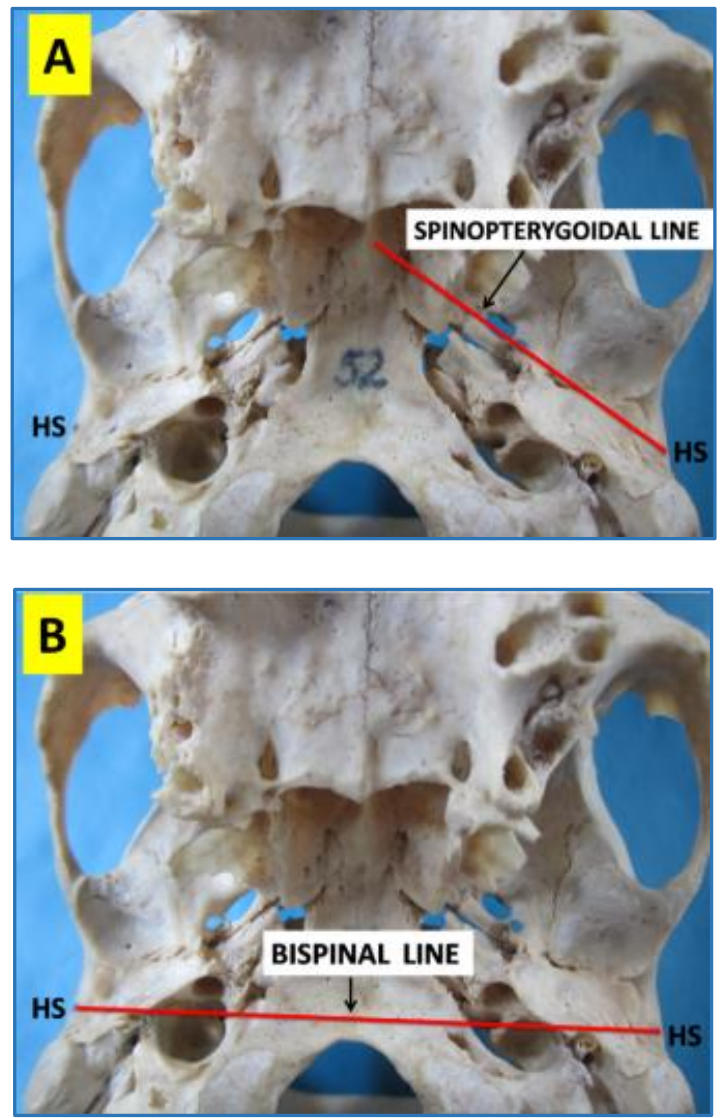

Fig. 3: Image A and B showing the Extent of Spinopterygoidal Line and Bispinal Line Respectively at the Base of Skull

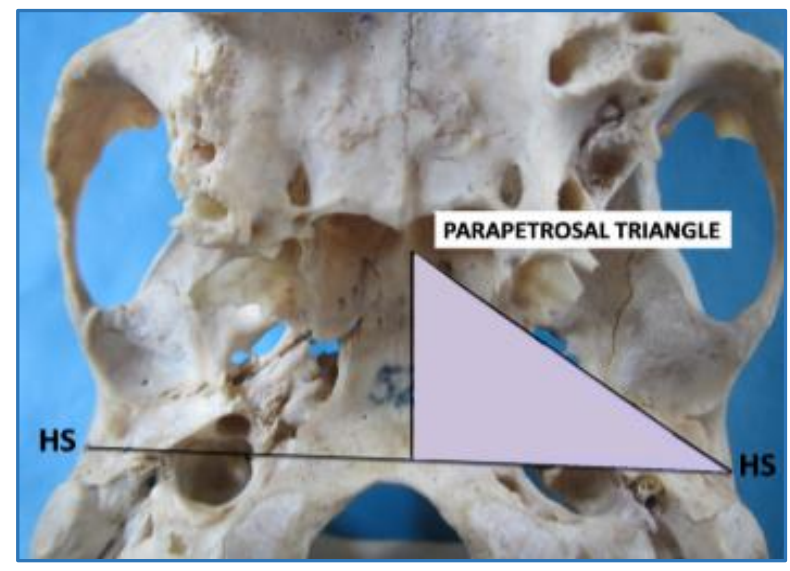

Fig. 4: Image showing the Extent of Parapetrosal Triangle (Shaded Area) at the Base of Skull

\section{DISCUSSION}

During neurosurgical exploration surgeries of the middle cranial fossa and the infratemporal fossa, the anatomic surface landmarks play an important guiding point to the operating surgeon to lead and explore the structures with accuracy and reliability.

In the present study, the mean difference between the right and left HS to posterolateral margin of jugular foramen was significantly different, being $22.33 \mathrm{~mm}$ and $23.31 \mathrm{~mm}$ respectively. The measured distances of the present study were less than the other reported studies by Ulug et al and Ray et al $(6,7)$, as tabulated in the Table 2 . The area around the jugular foramen of the cranial base is irregular with the foramen being at the junction of two bones, the occipital and petrous part of the temporal bone transmitting important neurovascular structures which warrants attention of the surgeon. The probable cause for the difference could have been the gender, racial difference with variability in methodology.

\section{LIMITATIONS}

The study had a few sources of possible bias. Even though the study was carried out after standardization of the method, it was subjective in nature. The present study used the skulls with prominent HS. The prevalence of absent HS is not uncommon. In such cases other surface landmarks should be considered.

\section{CONCLUSION}

Foramen ovale, carotid canal, jugular foramen appears to have a constant relationship to Henle's spine; hence, it can be used as a reliable surface landmark in skull base surgeries. However, the possibility of side difference should be kept in mind prior to surgeries involving jugular foramen.

\section{ACKNOWLEDGEMENT}

We acknowledge the invaluable assistance by the technicians of Department of Anatomy, St. John's Medical College, Bangalore.

\section{REFERENCES}

1. Shoma NM, Samya RN, Pensak ML. Radiographic assessment and surgical implications of arcuate eminence pneumatization. ORL 2016;78(1):9-15.

2. Demir MT, Kopuz C, Pirzirenli MEA. The localization of the asterion according to the anatomical landmarks of posterior cranial fossa in newborns: clinical implications. Int J Morphol 2015;33(2):685-94. 
3. Adoga SA, Mann ND, Benjamim T et al. Temporal bone dissection skill: a necessity for life otologic surgeries? Indian Journal of Otology 2011;17(2):71-4.

4. Hashomi J, Rajati M, Rezazani L, et al. Temporal bone measurement; a comparison between rendered spiral CT and surgery. Iran J Radiol 2014;11(3):e9400.

5. Jackson RCC. Morphologic and roentgenologic aspects of the temporal bone study of 536 bones with special reference to pneumatization Arch Otolaryngol 1938;28(5):748-67.
6. Ulug T, Ozturk A, Sahinoglu K. A multiple landmark for skull base surgery: Henle's spine. J Laryngol Otol 2005;119(11):856-61.

7. Ray B, Rajagopal KV, Rajesh T. Morphometry and CT measurements of useful bony landmarks of skull base. Romanian Journal of Morphology \& Embryology 2011;52(3):873-7. 